\title{
SKRINING PIGMEN KAROTENOID PADA KEPITING Grapsus sp. DENGAN MENGGUNAKAN PEMISAHAN KROMATOGRAFI
}

\author{
(Screening of Carotenoid Pigmen in Crabs of Grapsus sp. Using \\ Chromatography Separation)
}

\author{
Werianty Liony Zeak ${ }^{1}$, Darus Sa'adah J. Paransa ${ }^{{ }^{*}}$, Antonius Rumengan ${ }^{1}$, \\ Kurniati Kemer ${ }^{1}$, James J.H. Paulus ${ }^{1}$, Desy M.H. Mantiri ${ }^{2}$
}

\author{
${ }^{1}$ Program Studi Ilmu Kelautan, Fakultas Perikanan dan Ilmu Kelautan, Universitas Sam \\ Ratulangi, Manado \\ 2Jurusan Manajemen Sumber Daya Perairan, Fakultas Perikanan dan IImu Kelautan, \\ Universitas Sam Ratulangi, Manado \\ *Corresponding author: Darus Saadah J. Paransa, darusparansa@unsrat.ac.id
}

Grapsus sp. is one of the sea crustaceans that has a unique characteristic on its claws, which has a purplish and blackish green color on the carapace organ, this indicates that the crap carapace of Grapsus sp. has pigment content. From this pigment content that is then isolated to determine the type of pigment by using Thin Layer Chromatography and Column Chromatography. The carapace extract of Grapsus sp. crab which was isolated then analyzed, the result identified that the crab carapace of Grapsus sp. had the type of pigment B-Carotene, Echinenone, Cantaxanthin and Astaxanthin.

Keywords: Grapsus sp., Thin Layer Chromatography, Column Chromatography, Astaxanthin Pigments.

Grapsus sp. adalah salah satu krustasea laut yang memiliki ciri khas unik pada bagian capitnya yaitu memiliki warna keunguan dan hijau kehitaman pada organ karapas, hal ini menandakan bahwa karapas kepiting Grapsus sp. memiliki kandungan pigmen. Dari kandungan pigmen inilah yang kemudian diisolasi untuk mengetahui jenis pigmen dengan menggunakan pemisahan Kromatografi Lapis Tipis dan Kromatografi Kolom. Ekstrak karapas kepiting Grapsus sp. yang telah diisolasi kemudian di analisis, maka teridentifikasi bahwa karapas kepiting Grapsus sp. memiliki jenis pigmen B- Karoten, Ekinenon, Kantaxantin dan Astaxantin.

Kata Kunci: Grapsus sp., Kromatografi Lapis Tipis, Kromatografi Kolom, Pigmen Astaxantin.

\section{PENDAHULUAN}

\section{Latar Belakang}

Kepiting merupakan salah satu kekayaan laut, yang dapat ditemukan di bawah batu pinggir pantai, salah satu genus kepiting yaitu Grapsus sp. memiliki ciri khas warna hitam kehijauan yang berada pada organ karapas (Araujo, 2014). Karapas kepiting menampakan warna orange kemerah-merahan sebagai zat warna alami yang menandakan bahwa kepiting memiliki kandungan pigmen karotenoid. Menurut Britton (2008), pigmen karotenoid berperan penting bagi kesehatan manusia, sebagai provitamin A, antioksidan dan antikanker, sedangkan manfaat pigmen karatenoid pada kepiting Grapsus sp. adalah sebagai pro vitamin A, pertahanan dalam keadaan stres, pertahanan dalam menghadapi predator dengan cara perubahan warna kulit atau untuk melindungi diri dari keadaan yang buruk.

Analisis jenis pigmen karotenoid dapat dilakukan menggunakan pemisahan kromatografi lapis tipis dan juga kromatografi kolom. Paransa $d k k$ 
(2002), melaporkan hasil penelitiannya bahwa pigmen kantaxantin bermigrasi di bawah pigmen tipe ekinenon pada organ dalam dan organ luar dari kepiting Grapsus sp. yang ditangkap dari pantai di daerah perbatasan Kalasey-Manado, pada penelitiannya menggunakan metode kromatografi lapis tipis. Berdasarkan penelitian (Paransa dkk, 2014), bahwa pigmen tipe ekinenon juga memiliki peranan lain yaitu sebagai aktivitas antibakteri pada 4 bakteri uji (E.coli, Klebsiella pneumonia, Salmonella paratiphy $b$ dan Staphylococcus aerus), dengan menggunakan pemisahan kromatografi kolom dan serapan spektrofotometer UV-Vis.

Pada penelitian yang dilakukan oleh Thamin dkk, (2006) untuk memisahan pigmen dari suatu organisme dilakukan dengan memanfaatkan larutan pengembang semi-polar. Pemisahan pigmen karotenoid pada krustasea dilakukan dengan memanfaatkan larutan Petroleum eter (PE). Hasil yang diperoleh dari penelitian (Abdullah $d k k, 2018)$ bahwa pigmen karotenoid juga terdistribusi pada organ karapas, lapisan epidermis, hepatopankreas dan gonad dari kepiting Grapsus sp dengan menggunakan pemisahan kromatografi lapis tipis.

\section{Tujuan Penelitian}

dalam penelitian ini yaitu, mengidentifikasi jenis-jenis pigmen pada karapas Grapsus sp dengan metode pemisahan Kromatografi Lapis Tipis dan Kromatografi Kolom.

\section{METODE PENELITIAN}

Pada penelitian ini, sampel diambil dari pesisir pantai berbatu Desa Ranowangko, Kecamatan Tombariri, Kabupaten Minahasa, Provinsi Sulawesi Utara. Kepiting yang baru melakukan pergantian kulit biasanya bersembunyi di bawah batu. Pengambilan sampel dilakukan pada malam hari dan di tangkap menggunakan tangan, lokasi pengambilan sampel tertera pada (Gambar 1).
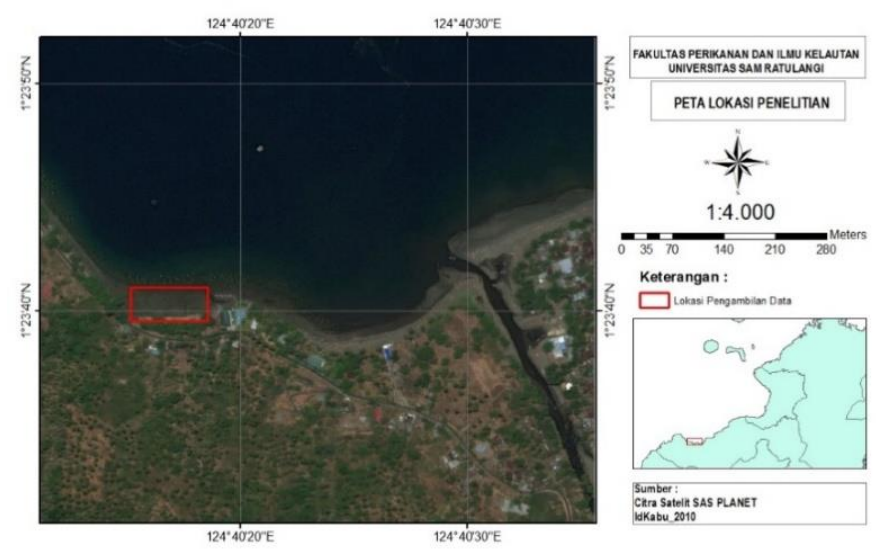

Gambar.1 Peta Lokasi Penelitian Desa Ranowangko. Sumber: Peta Citra Satelit, 2010

\section{Ekstraksi}

Karapas kepiting $\begin{gathered}\text { diekstrak } \\ \text { sebanyak } 3 \text { gram direndam }\end{gathered}$
menggunakan larutan $\mathrm{HCl} 2 \mathrm{~N}$.
Karapas digerus dan diberikan
larutan aceton serta hasil ekstraknya
di saring ke dalam labu pemisah.
Selanjutnya diberikan larutan heksan
maka terjadi pemisahan antara
lapisan atas dan lapisan bawah,
lapisan atas adalah larutan
supernatan pigmen dalam larutan
heksan.

\section{Pemisahan Ekstrak Pigmen} dengan Kromatografi Lapis Tipis

Untuk mendapatkan jenis pigmen karotenoid pada ekstrak pigmen total karapas kepiting dilakukan melalui pemisahan Kromatografi Lapis Tipis (KLT). Diawali penyiapan sampel yang telah diekstrak, plat silika Gel Tipe G60 sebagai fase diam dan larutan pengembang sebagai fase gerak. 


\section{Pemisahan Ekstrak Pigmen dengan Kromatografi Kolom \\ Ekstrak pigmen total} dipisahkan menggunakan kromatografi kolom bertujuan untuk mendapatkan jenis pigmen dengan cara diisolasi dengan bahan utama yaitu sampel karapas kepiting. Penyiapan media kolom, bubuk silika sebagai fase diam dan larutan pengembang sebagai fase gerak, bubuk silika Gel 9 gram dan

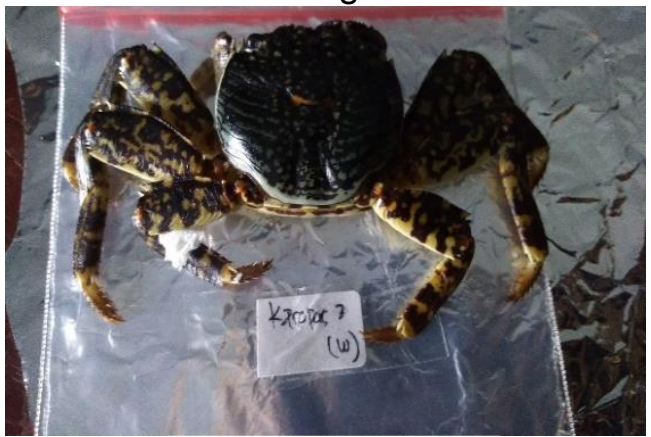

Dorsal dipanaskan dalam oven selama 24 jam.

\section{HASIL DAN PEMBAHASAN}

Sampel kepiting yang digunakan pada penelitian ini diidentifikasi berdasarkan bentuk morfologi dengan merujuk pada Majchacheep (1989). Sampel kepiting tampak pada (Gambar 2).

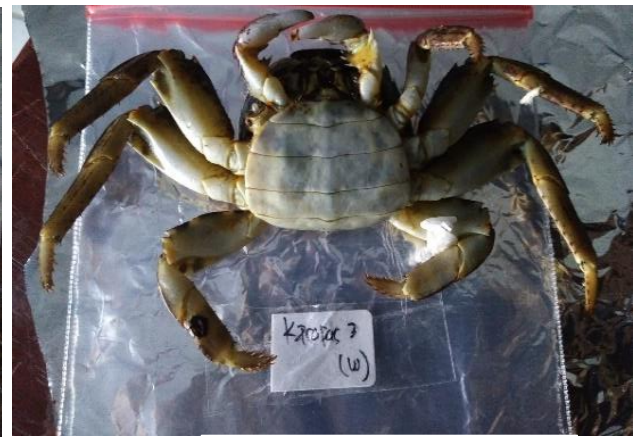

Ventral

Gambar. 2 Sampel Grapsus sp.

Sumber: Milik Pribadi, 2019

Kepiting ini teridentifikasi sebagai Grapsus sp. dengan ciri khas terdapat pada bagian capitnya yaitu memiliki warna keunguan dan garis garis linier berwarna hijau kehitaman pada dorsal karapas. Permukaan tampak depan terdapat garis berwarna kehijauan. yang hidup di pantai berbatu di daerah tropis. Pada saat ekstraksi sampel yang digunakan sebanyak 4 ekor dengan panjang rata-rata $7 \mathrm{~cm}$ serta berat segar masing-masing karapas 3 gram.

Kandungan dan konsentrasi pigmen karotenoid diperoleh melalui serapan maksimum spektrofotometer diantara panjang gelombang $380-550 \mathrm{~nm}$. Bentuk spectrogram tersebut tampak pada Gambar 3.

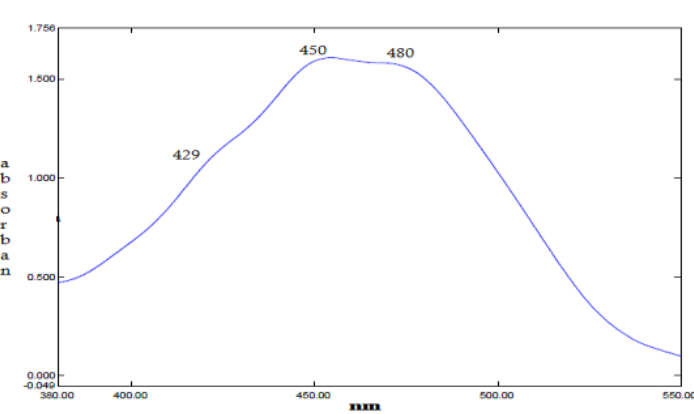

Gambar 3. Spektrogram Ekstrak Pigmen Total Karapas Kepiting Grapsus sp.

Puncak serapan spektrogram ekstrak pigmen total karapas Grapsus sp. seperti yang tampak pada (Gambar 3), terdapat pada panjang gelombang 429, 450, 480 nm. Menurut Britton dkk, (1995) Bentuk spektrogram tersebut belum dapat teridentifikasi jenis pigmen karotenoid, diasumsikan masih terjadi pencampuran jenis pigmen maka ekstrak pigmen total tersebut 
dilanjutkan dengan pemisahan kromatografi kolom.

Berdasarkan

serapan

maksimum spektrofotometer UV-Vis pada ekstrak pigmen total organ karapas kepiting Grapsus sp. dapat menentukan nilai kandungan (Q) dan konsentrasi pigmen (C). Hasil perhitungan konsentrasi dan kandungan pigmen karotenoid pada ekstrak pigmen total organ karapas kepiting Grapsus sp. pada hitungan rata-rata konsentrasi pigmen (C)/berat residu kering 3,88 / $\mu \mathrm{g} / \mathrm{gr}$ sedangkan rata-rata Kandungan Pigmen (Q) 8,42 $\mu \mathrm{g}$.

\section{Hasil Pemisahan Ekstrak Pigmen Total dengan Kromatografi Kolom dan Kromatografi Lapis Tipis}

Jenis pigmen yang terdapat pada hasil Kromatografi Kolom terdapat empat fraksi sedangkan Kromatografi Lapis Tipis terdapat lima fraksi yang tertera pada Tabel 2.

Tabel 2. Pemisahan Ekstrak Pigmen Total dengan Kromatografi Kolom dan Kromatografi Lapis Tipis

\begin{tabular}{|c|c|c|c|c|c|c|c|}
\hline F & \multicolumn{3}{|c|}{ KROMATOGRAFI LAPIS TIPIS } & \multicolumn{3}{c|}{ KROMATOGRAFI KOLOM } \\
\hline \multicolumn{2}{|c|}{ RF } & $\begin{array}{c}\text { Panjang } \\
\text { Gelomban } \\
\text { g } \\
\text { nm }\end{array}$ & Warna & Jenis Pigmen & Warna & $\begin{array}{c}\text { Panjang } \\
\text { Gelombang } \\
\text { nm }\end{array}$ & Jenis Pigmen \\
\hline 1 & 0,1 & $\begin{array}{c}426,450, \\
475\end{array}$ & Kuning & B-Karoten & $\begin{array}{c}\text { Orange } \\
\text { Pekat }\end{array}$ & 462 & Ekinenon \\
\hline 2 & 0,93 & 460 & Orange & Ekinenon & Orange & 475 & Kantaxantin \\
\hline 3 & 0,88 & 475 & Merah & Kantaxantin & $\begin{array}{c}\text { Orange } \\
\text { Pekat }\end{array}$ & 480 & Astaxantin \\
\hline 4 & 0,67 & - & Orange & $\neq$ & Kuning & - & $\neq$ \\
\hline 5 & 0,63 & - & Kuning & $\neq$ & - & - & - \\
\hline
\end{tabular}

Ket $: \mathbf{F}=$ Fraksi $\neq=$ Tidak teridentifikasi

\section{Hasil Serapan Spektrofotometer Kromatografi Lapis Tipis dan Kromatografi Kolom pada Masing- masing Fraksi FRAKSI 1}

Fraksi 1 serapan spektrogram Pemisahan Kromatografi Lapis Tipis (A)

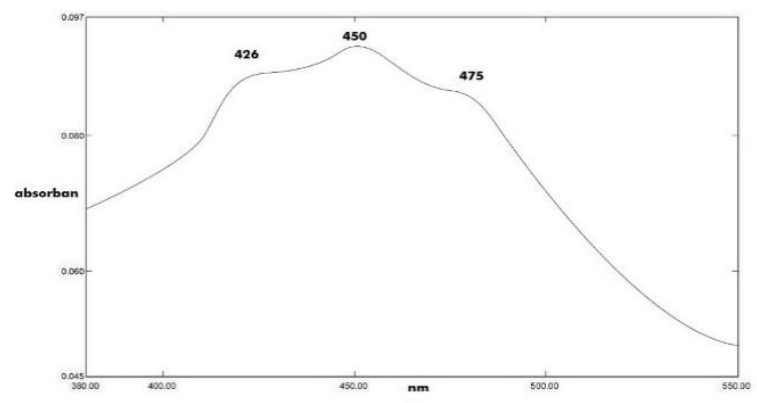

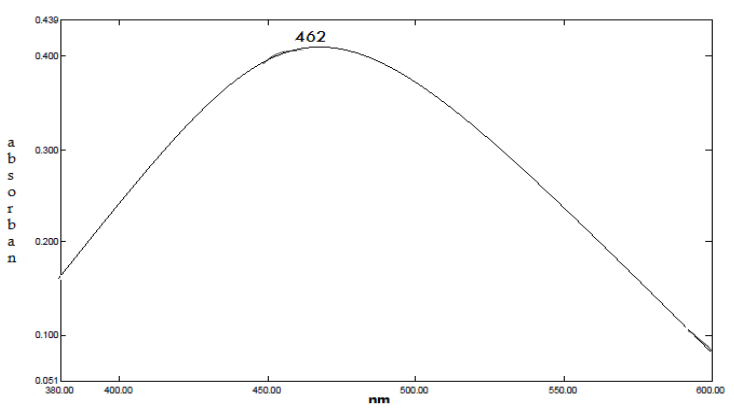

'ambar 4. Bentuk spektrogram (A): Jenis pigmen ßKaroten ; (B) Jenis Pigmen Ekinenon

Berdasarkan (Gambar 4A) memiliki nilai $\mathrm{Rf} 0,1$. Fraksi ini setelah melalui serapan maksimum spektrofotometer, membentuk dua

Fraksi 1 serapan spektrogram Pemisahan 
puncak dan satu lekukan pada panjang gelombang 425,450 dan $475 \mathrm{~nm}$. Menurut Britton dkk (1995), puncak gelombang 425,450 dan $475 \mathrm{~nm}$, sehingga fraksi ini juga teridentifikasi sebagai pigmen $\beta$ karoten. Hasil penelitian Balaira $d k k$, (2017) ditemukan pada alga Dunaliella salinayang juga ditemukan jenis pigmen $\beta$-karoten pada $\mathrm{Rf} 1$ dengan pengembang $\mathrm{PE}$ Aseton (80:20).

Tampak juga pada (Gambar 4B) setelah melalui serapan maksimum spektrofotometer UV-Vis, membentuk satu puncak gelombang dengan panjang gelombang $462 \mathrm{~nm}$. Britton dkk (1995) mengemukakan pigmen ekinenon dapat terbentuk karena masuknya gugus keton $(=0)$ pada salah satu rantai siklik pigmen $\beta$-karoten, pigmen tipe ekinenon juga memiliki warna orange pekat.

\section{FRAKSI 2.}

Fraksi 2 serapan spektrogram Pemisahan Kromatografi Kolom

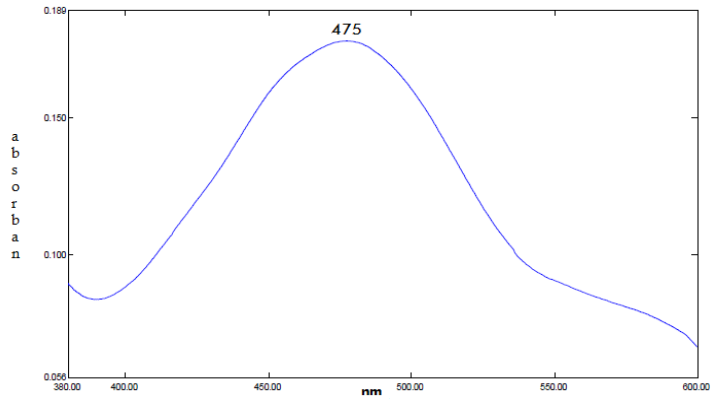

Gambar 5. Serapan Maksimum Spektrofotometer Jenis Kantaxantin

Berdasarkan (Gambar 5) memiliki hasil serapan maksimum spektrofotometer berada pada panjang gelombang $475 \mathrm{~nm}$. Menurut Britton $d k k$ (1995), pita ini teridentifikasi sebagai pigmen kantaxantin. Paransa dkk (2002), melaporkan hasil penelitiannya bahwa pigmen kantaxantin bermigrasi di bawah pigmen tipe ekinenon pada organ dalam dan organ luar dari kepiting Grapsus sp. yang ditangkap dari pantai di daerah perbatasan Kalasey-Manado, pada penelitiannya menggunakan metode kromatografi lapis tipis.

Pada fraksi 2 memiliki dua jenis pigmen yaitu ekinenon pemisahan kromatografi lapis tipis dan kantaxantin, pembahasan mengenai pigmen ekinenon tertera pada (Gambar 4B).

\section{FRAKSI 3}

Fraksi 3 serapan spektrogram Pemisahan Kromatografi Kolom

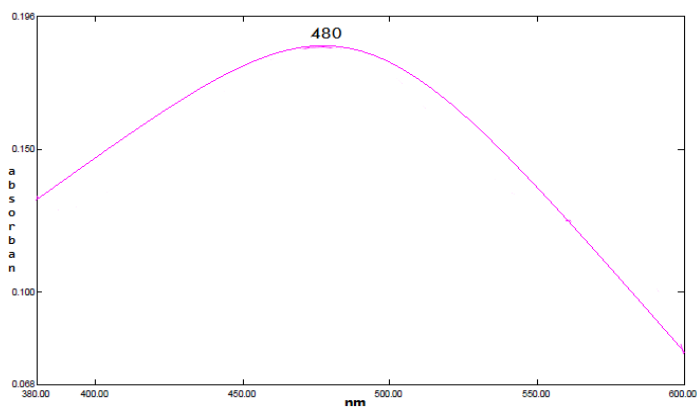

Gambar 6. Serapan Maksimum Spektrofotometer Jenis Astaxantin

$$
\begin{aligned}
& \text { serapan maksimum } \\
& \text { spektrofotometer UV-Vis berada } \\
& \text { pada panjang gelombang } 480 \mathrm{~nm} \text {. } \\
& \text { Menurut Britton } d k k \text {, (1995) bahwa } \\
& \text { serapan maksimum panjang } \\
& \text { gelombang pada } 480 \quad \mathrm{~nm} \\
& \text { teridentifikasi sebagai pigmen } \\
& \text { astaxantin. }
\end{aligned}
$$$$
\text { Berdasarkan (Gambar 6) hasil }
$$

Menurut Bliss dan Mantel (1985), pigmen astaksantin terdistribusi pada semua organ tubuh krustasea hal inilah yang menyebabkan terjadinya visualisasi warna yang unik yang digunakan dalam proses fotobiologi. Selanjutnya Ruppert dan Barnes (1994) mengatakan bahwa pigmen astaksantin merupakan pigmen mayor pada krustasea. Britton $d k k$ (1995) mengemukakan bahwa pigmen astaksantin bersifat semipolar karena mengandung 2 
gugus karbonil dan 2 gugus hidroksil. Pada fraksi ke-3 memiliki dua jenis pigmen yaitu kantaxantin dan astaxantin, untuk gambar dan pembasan jenis pigmen kantaxantin dapat dilihat pula pada (Gambar 5).

\section{FRAKSI 4 dan 5}

Fraksi ke-4 dan ke-5 untuk panjang gelombang dan jenis pigmen pada pita keempat tidak teridentifikasi karena setelah di isolasi tidak teridentifikasi jenis pigmen berdasarkan Britton $d k k$, (1995).

\section{KESIMPULAN}

Dari hasil penelitian ini, dapat disimpulkan sebagai berikut:

Ekstrak karapas kepiting Grapsus sp. yang telah diisolasi kemudian di analisis, maka teridentifikasi bahwa karapas kepiting Grapsus sp. memiliki jenis pigmen ß- Karoten, Ekinenon, Kantaxantin dan Astaxantin.

\section{DAFTAR PUSTAKA}

Abdullah. M.R.A. Paransa D.S.J. Mantiri D.M.H. Angkow E.D. Angmalisang P.A. Mudeng. J.D. 2018. Distribusi Pigmen Karotenoid Pada Kepiting Grapsus sp Dengan Menggunakan Metode Kromatografi Lapis Tipis. Jurnal Pesisir dan Laut Tropis. Vol. 2 No. 1 Tahun 2018. Hal 23-24.

Araujo M.L. 2014. The Leaping Behavior of the Sally Lightfoot Crab Grapsus Grapsus (Crustacea: Decapoda: Brachyura) at an Oceanic Archipelago. Journal of Research in Biology. JRB 2014. Vol.4 No.4. 1357-1364.
Balaira, G.Y., Kemer, K., dan Mantiri, D.M.H. 2017. Pemisahan Pigmen Pada Mikroalga Dunaliella salina Yang Telah Diberi Senyawa Timbal Asetat. Jurnal Pesisir dan Laut Tropis. Volume 1 No. 1 Tahun 2017.

Bliss, D.E. 1982. Systematics, The Fossil Record and Biogeography in The Biologi of Crustacea. Vol 1, New York. Amirica

Britton, G., S.L. Jansen and H. Pfander. 1995. Caratenoids. Volume 1A. Spectroscopy. Basel, Switzerland. Hal. 347

Britton, G., S.L. Jansen and H. Pfander. 2008. Carotenoids. Volume 4. Natural Functions. Basel, Switzerland.

Lorenz, R.T. dan Cysewski, G.R. Commercial potential for Haematococcus microalgae as a natural source of astaxanthin. Trends Biotechnol. 2000: 18: 160-7.

Majchacheep, S. 1989. Marine Animal Of Thailand. Published By Prae Pittaya. Thailand.

Mantiri, D.M.H., Nègre-Sadargues, G., Milicua J.C.G., Castillo, R. 2004 The Carotenoproteins During Embryogenesis and Larval Development of the European Lobster Homarus Gammarus. Journal of Crustacean Biology, 24 (4) : 592-602.

Maoka, T. 2011. Carotenoids in Marine Animals. Review. Research Institute for Production Development. Japan. 
Paransa, D.J. D.H.M. Mantiri, F. Korompis. 2002. Penentuan Kandungan Pigmen Karatenoid Pada Kepiting Grapsus albolineatus (Lamarck) Betina Berdasarkan Beda Larutan Pengembang Pada Kromatografi Lapis Tipis. Jurnal Perikanan Dan IImu Kelautan. Vol 1. No. 32002. FPIK. UNSRAT.

Paransa, D.J. Kemer, K. Rumengan A.P. D.H.M. Mantiri. 2014. Analisis Jenis Pigmen Dan Uji Aktivitas Antibakteri Ekstrak Pigmen Xantofil Pada Alga Coklat Sargassum polycystum (C.Agardh). Jurnal LPPM Bidang Sains dan Teknologi.Vol.1 No.1 2014. Hal 92-95.

Pratiwi. R dan Limantara.L. 2010. Potensi Astaxantin sebagai Senyawa Antikanker. Indonesian Journal of Cancer. Hal. 149.

Ruppert, E.E. dan Barnes, R.D. 1994. Invertebrata Zoology. Clemson University, Soutcorolini. Gettysburg College, Pennsylvania.

Thamin A. Chairulwan U. Paransa D. 2006. Analisis Pigmen dan Aktivitas Antibakteri In Vitro Pigmen Astaksantin Kepiting (grapsus albolineatus lamarck) Jantan. Jurnal Perikanan UNSRAT. 